\title{
Mammogram history in Nigerian women: Age-related risk factors for breast cancer and educational implications
}

\begin{tabular}{|c|c|}
\hline \multicolumn{2}{|c|}{$\begin{array}{l}\text { Authors: } \\
\text { Eric O. Umeh } 1 \\
\text { Kanayo F. Umeh } \\
\text { Uzoamaka R. Ebubedike } \\
\text { Chiamaka F. Ezeugbor }^{2} \text { (1) } \\
\text { Chukwuziem N. Anene }^{3}\end{array}$} \\
\hline \multicolumn{2}{|c|}{ 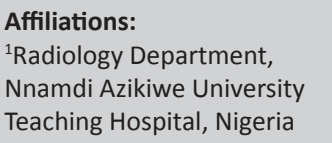 } \\
\hline \multicolumn{2}{|c|}{$\begin{array}{l}{ }^{2} \text { School of Natural Sciences } \\
\text { and Psychology, Liverpool } \\
\text { John Moores University, } \\
\text { United Kingdom }\end{array}$} \\
\hline \multicolumn{2}{|c|}{$\begin{array}{l}{ }^{3} \text { Radiology Unit, Iyienu } \\
\text { Mission Hospital, Nigeria }\end{array}$} \\
\hline \multicolumn{2}{|c|}{$\begin{array}{l}\text { Corresponding author: } \\
\text { Kanayo Umeh, } \\
\text { f.k.umeh@ljmu.ac.uk }\end{array}$} \\
\hline \multicolumn{2}{|c|}{$\begin{array}{l}\text { Dates: } \\
\text { Received: } 21 \text { May } 2018 \\
\text { Accepted: } 25 \text { June } 2018 \\
\text { Published: } 31 \text { July } 2018\end{array}$} \\
\hline \multicolumn{2}{|c|}{$\begin{array}{l}\text { How to cite this article: } \\
\text { Umeh EO, Umeh KF, } \\
\text { Ebubedike UR, Ezeugbor CF, } \\
\text { Anene CN. Mammogram } \\
\text { history in Nigerian women: } \\
\text { Age-related risk factors for } \\
\text { breast cancer and educational } \\
\text { implications. S. Afr. j. oncol. } \\
2018 ; 2(0), \text { a45. https://doi. } \\
\text { org/10.4102/sajo.v2iO.45 }\end{array}$} \\
\hline \multicolumn{2}{|c|}{$\begin{array}{l}\text { Copyright: } \\
\text { (c) 2018. The Authors. } \\
\text { Licensee: AOSIS. This wc } \\
\text { is licensed under the } \\
\text { Creative Commons } \\
\text { Attribution License. }\end{array}$} \\
\hline \multirow[b]{2}{*}{ 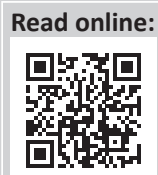 } & \\
\hline & $\begin{array}{l}\text { Scan this QR } \\
\text { code with your } \\
\text { smart phone or } \\
\text { mobile device } \\
\text { to read online. }\end{array}$ \\
\hline
\end{tabular}

Background: Breast cancer accounts for $25 \%$ of diagnosed cancers and $20 \%$ of cancer-related mortality in women from sub-Saharan Africa. Given the early onset of breast cancer in African women, there is a need to better understand how age-related risk factors contribute to mammography uptake in this population.

Aim: To identify age-related risk factors for breast cancer associated with previous uptake of mammograms in asymptomatic Nigerian women and consider implications for health education campaigns.

Method: Participants comprised 544 asymptomatic Nigerian women (aged 28-75 years) responding to breast cancer public awareness campaigns, by presenting for baseline or screening mammography at a local hospital. Information about mammography history and age-related risk factors (menarche, menopausal and chronological age) were obtained by interviewing the participants face-to-face, before proceeding with mammography. Hierarchical logistic regression was used to estimate the odds of previous mammograms based on the age-related risk factors.

Results: The likelihood of previous mammography screening increased by a factor of 1.07 (95\% confidence interval [CI]: 1.00-1.14) for every year older chronologically and decreased by a factor of 1.12 (95\% CI: 1.24-1.01) for every year older at menarche. Age at menarche partly mediated the relationship between chronological age and mammography history (effect $=-0.01,95 \%$ CI: $-0.01,-0.00$ ). Women with a history of breast cancer were 6.11 times more likely to have previously undertaken mammography screening (95\% CI: 2.49-14.97). Age at menopause and age at first confinement were unrelated to mammography history.

Conclusions: Nigerian women may recognise the need for mammograms because of adverse age-related risk factors for breast cancer, notably menarche and chronological age. However, awareness of menopausal age as a risk factor and basis for mammography screening may be deficient. It is therefore recommended that public awareness campaigns should emphasise the importance of older menopausal age in breast cancer risk and as a basis for requesting mammograms.

\section{Background}

Breast cancer accounts for $25 \%$ of diagnosed cancers and $20 \%$ of cancer-related mortality amongst women in sub-Saharan Africa. ${ }^{1}$ Data from the International Agency for Research on Cancer suggest about 100000 breast cancer cases are diagnosed annually in the African region, with the largest number of country-specific cases diagnosed in Nigeria (circa 14000 ) yearly. ${ }^{2}$ While the breast cancer incidence and mortality rates remain highest in fully industrialised nations, rates are rapidly increasing in developing countries. Thus, there is a dire need to detect cancer early, when it is more responsive to treatment. ${ }^{3}$ Mammography is a breast imaging method that employs low-dose x-rays to detect cancer early, thereby reducing the incidence of advanced cancers with poor prognosis. ${ }^{3}$ Mammography screening in Nigeria is offered to women aged from 40 to 70 years, ${ }^{4}$ although women under 40 years may also be invited for mammograms if they have a strong family history of breast cancer. ${ }^{5}$ The efficacy of mammography in younger women is debatable (because of higher breast density). ${ }^{6}$ Nevertheless, missing a mammogram can significantly increase the likelihood of being diagnosed with cancer at a later stage. ${ }^{7}$ 


\section{Age-related risk factors}

Several age-related risk factors for breast cancer have been identified. ${ }^{8}$ Therefore, these factors must be considered in health education initiatives to improve breast cancer awareness. ${ }^{9}$ Breast cancer patients from sub-Saharan Africa are often of a younger chronological age, with an average age of onset of 35-49 years, ${ }^{10}$ compared to around 71 years in European women. ${ }^{11}$ The majority of breast cancer cases diagnosed in Africa occur in women aged $\leq 50$ years. ${ }^{12}$ Research also suggests age at menarche is critical in Nigerian women with younger age at first menstruation being associated with elevated breast cancer risk. ${ }^{8,13}$ Finally, age at menopause has also been implicated in breast cancer risk, with older age at menopause being associated with greater risk. ${ }^{14}$ Given the early onset of breast cancer in African women, there is a need to better understand the link between age-related risk factors and mammography uptake in this population.

\section{Educational challenges}

The importance of education about breast cancer risk in Nigeria is underscored by the low levels of breast cancer awareness in this region, ${ }^{15}$ even amongst health professionals, including medical doctors, nurses and radiographers. ${ }^{16,17,18}$ One study found only $38.2 \%$ of doctors and $18.9 \%$ of nurses knew that increasing age was a risk factor for breast cancer. ${ }^{16}$ Thus, Nigerian health workers may fail to offer mammography screening to women with negative age-related risk factors. Furthermore, Nigerian women may delay or decline mammograms partly because of knowledge deficits on breast cancer, ${ }^{19}$ including age-related risk factors. ${ }^{20}$ Even amongst women who are more knowledgeable about breast cancer (e.g. those with higher education or professional jobs), ${ }^{20}$ psychological theories of aging would suggest an age-related aversion to risk information may discourage utilisation of diagnostic medical services that may confirm the presence of a life-threatening illness. ${ }^{21}$ As many Nigerians view cancer as a spiritual ailment, older age may increase preference for traditional healers, who may present a more positive outlook for the future, through spiritual incantations and local herb preparations. $^{22}$

Whereas health promotion initiatives in many Western countries target women over 50 for breast cancer screening, ${ }^{23}$ most sub-Saharan African countries lack a formal nation-wide breast cancer-screening programme.22 Thus, many women have little or no education about the importance of age-related risk factors in mammography screening. ${ }^{15}$ Nigerian women are disinclined to use medical services (e.g. visit a hospital) for menopause-related problems: one study found only $25.4 \%$ of women sought medical assistance because of menopause. ${ }^{24}$ Thus, it is possible that older age at menopause may fail to encourage mammography, particularly given the low levels of cancer awareness..$^{20}$ Evidence on menarche age and use of medical services by Nigerian women seems non-existent. ${ }^{22}$ Thus, it is unclear whether women who are currently eligible for breast cancer screening will be motivated to undergo a mammogram as a result of having experienced menarche at a younger age in their youth.

\section{The present study}

Ages at menarche and menopause are particularly critical milestones in a woman's lifespan and linked to adverse biomedical (and psychosocial) outcomes. ${ }^{25}$ Menopausal age is the final stage in ovarian aging, while age at first menstruation marks the beginning of the female reproductive cycle. ${ }^{26}$ Women may seek or be offered mammography because of adverse age-related risk factors. However, these scenarios assume an adequate level of education about age-related risk factors for breast cancer, in both women and health professionals. Given the low level of breast cancer education in sub-Saharan Africa, ${ }^{15,16,20}$ including knowledge of risk factors, ${ }^{15,16}$ this study had two aims. The first objective was to determine whether women with adverse age-related risk factors for breast cancer are more likely to have a history of mammography screening. The second objective was to identify specific areas where education about age-related risk factors and importance of mammograms needs to be improved.

\section{Methodology Sample}

The cohort comprised 544 asymptomatic women (aged 28-75 years) presenting for screening mammography at the Shell-Iyienu Mission hospital breast cancer-screening programme in Anambra State, Nigeria, between January 2014 and December 2016. The programme accepts women aged 40 years and above for screening mammography, as well as women aged between 25 and 39 years with a positive history of breast cancer in the family. Although mammography screening in Nigeria targets women aged between 40 and 70 years, women under 40 years may be invited for a mammogram if they have a strong family history of breast cancer. $^{5}$

\section{Mammography history and age-related risk factors}

Past medical and family histories were obtained by interviewing the participants face-to-face and entering the information into a data form, before proceeding with mammography. The information recorded included participant's height, weight, age, age of menarche, age at menopause, family history of breast cancer (including firstdegree relative), history of previous mammogram, presence of breast symptoms (breast pain, palpable breast lump and nipple discharge) and previous history of breast disease. While taking her mammography history, each woman was simply asked if she had previously had a mammogram. Responses were recorded in a 'Yes' or 'No' format.

After taking her clinical history, each woman underwent a physical breast examination, both carried out by trained registered nurse, followed by the mammography procedure. 
Any women unable to provide definite responses to questions during the face-to-face interview were excluded from this study.

\section{Data analysis}

We used hierarchical logistic regression models to estimate the odds ratios ([ORs], 95\% confidence intervals [CIs]) of previous mammography, based on age-related risk factors, and adjusting for personal and family history of breast cancer. Age-related risk factors were entered in Step 1, followed by personal history of breast cancer in Step 2, family history of breast cancer in Step 3 and finally having a first-degree relative with breast cancer in Step 4. Age-related risk factors were assessed before family history, to assess their unique contribution to mammography history, before accounting for family history. The results are presented in Table 2 .

To shed more light on possible direct and indirect associations involving age-related risk factors, we assessed the extent to which the association between chronological age and mammography screening was mediated by menarche or menopausal age. ${ }^{25}$ The analysis was performed using the PROCESS macro dialogue Statistical Package for the Social Sciences (SPSS) bootstrapping protocol..$^{27,28}$ This generates unstandardised regression or path coefficients. We specified the generation of 1000 bootstrap samples, with a biascorrected CI method. ${ }^{27,28}$ For both predictor and mediator variables, 95\% Ordinary Least Squares (OLS)-Maximum Likelihood (ML) Estimation CIs were specified. The conservative 'normal theory' (i.e. Sobel) test was used to establish the significance of any mediator effects. ${ }^{29,30}$ Statistical significance was based on $\alpha=0.05$. SPSS version 23 (IBM Corporation, Armonk, New York, USA), incorporating the PROCESS macro dialogue ${ }^{27}$ was used for data analysis.

\section{Ethical considerations}

This work received approval from Liverpool John Moores University Research Ethics Committee (UREC) - Ethics Approval Reference 17/NSP/042.

\section{Results \\ Descriptive statistics}

Table 1 shows descriptive data for the entire sample, and respondents with and those without prior mammography history. Only 52 women (9.6\%) had a previous history of mammography screening. About $13 \%$ of respondents had a palpable lump and previous history of breast cancer. Just under 1 in 10 had a previous biopsy, and $4.4 \%$ had a positive family history of breast cancer (with around $4 \%$ having a first-degree relative with breast cancer). The average chronological age of the sample was just under 50 years, while the mean age at first confinement was around 23 years. Average age at menarche was just over 13 years, while the mean age at menopause was about 47 years. The average height and weight were 2.16 metres and $82.14 \mathrm{~kg}$, respectively.

When comparing women with and without a history of previous mammography, several significant patterns emerged. Those with a history of previous mammograms

TABLE 1a: Descriptive statistics.

\begin{tabular}{|c|c|c|c|c|}
\hline \multirow[t]{3}{*}{ Variables } & \multicolumn{4}{|c|}{ Mammography history } \\
\hline & Sample & $\begin{array}{c}\text { Previous history of } \\
\text { mammography }\end{array}$ & $\begin{array}{c}\text { No previous history of } \\
\text { mammography }\end{array}$ & $P$ \\
\hline & Mean \pm SD & Mean \pm SD & Mean \pm SD & \\
\hline Chronological age & $49.10 \pm 8.13$ & $53.42 \pm 8.65$ & $48.64 \pm 7.94$ & $<0.001$ \\
\hline Age at first confinement & $23.09 \pm 9.31$ & $21.88 \pm 10.86$ & $23.22 \pm 9.13$ & 0.32 \\
\hline Menarche age & $13.36 \pm 3.56$ & $12.28 \pm 4.27$ & $13.47 \pm 3.46$ & $<0.05$ \\
\hline Menopause age & $47.44 \pm 4.57$ & $48.66 \pm 4.20$ & $47.27 \pm 4.60$ & 0.10 \\
\hline Height & $2.16 \pm 8.71$ & $2.94 \pm 9.43$ & $2.08 \pm 8.63$ & 0.50 \\
\hline Weight & $82.14 \pm 17.69$ & $80.18 \pm 20.50$ & $82.34 \pm 17.38$ & 0.40 \\
\hline
\end{tabular}

Note: Independent $t$-tests were used to compare women with and without a mammography history on age-related risk factors, and also height and weight. Chi-square was used to compare groups on family history and the other nominal (i.e. categorical) variables.

SD, Standard deviation.

TABLE 1b: Descriptive statistics.

\begin{tabular}{|c|c|c|c|c|}
\hline \multirow[t]{3}{*}{ Variables } & \multicolumn{4}{|c|}{ Mammography history } \\
\hline & Sample & $\begin{array}{l}\text { Previous history of } \\
\text { mammography }\end{array}$ & $\begin{array}{c}\text { No previous history of } \\
\text { mammography }\end{array}$ & $P$ \\
\hline & $n(\%)$ & $n(\%)$ & $n(\%)$ & \\
\hline Palpable lump (yes) & $73(13.4)$ & $0(0.0)$ & $73(14.8)$ & $<0.001$ \\
\hline Personal history of breast cancer (yes) & $72(13.2)$ & $15(28.8)$ & $57(11.6)$ & $<0.001$ \\
\hline History of biopsy (yes) & $49(9.0)$ & $11(21.2)$ & $38(7.7)$ & $<0.01$ \\
\hline Mammography (yes) & $52(9.6)$ & $\mathrm{n} / \mathrm{a}$ & $\mathrm{n} / \mathrm{a}$ & - \\
\hline Family history of breast cancer (yes) & $43(7.9)$ & $3(5.8)$ & $40(8.1)$ & 0.39 \\
\hline Family history of gynaecological cancer (yes) & $13(2.4)$ & $1(1.9)$ & $12(2.4)$ & 0.64 \\
\hline Family history (first-degree relative with breast cancer) (yes) & $24(4.4)$ & $2(3.8)$ & $22(4.5)$ & 0.59 \\
\hline
\end{tabular}

Note: Independent $t$-tests were used to compare women with and without a mammography history on age-related risk factors, and also height and weight. Chi-square was used to compare groups on family history and the other nominal (i.e. categorical) variables.

SD, Standard deviation. 
were less likely to have a palpable lump $(p<0.001)$, more likely to have a history of breast cancer $(p<0.001)$ and more likely to have had a previous biopsy $(p<0.01)$. There was no group difference in familial risk, including having a first-degree relative with breast cancer. Women with a mammography history were more likely to be older than median menopausal age for the sample $(p<0.001)$. These women were also chronologically older, but younger at menarche $(p<0.05)$. There were no group differences in age at first confinement, age at menopause and height or weight data.

\section{Association between age-related risk factors and mammography history}

Table 2 shows the results of hierarchical logistic regression predicting mammography history from age-related risk factors and other factors. No age-related risk factor emerged as a significant predictor in Step 1, albeit chronological age and age at menarche both approached significance $(p=0.06$ and 0.09 , respectively). In Step 2, personal history of breast cancer made a significant contribution and seemed to have a positive confounding effect on chronological age and age at menarche, which were now both significant predictors. Finally, neither family history nor having a first-degree relative with breast cancer accounted for significant proportions of the variance in mammography history, when added in Steps 3 and 4, respectively. In the final model, chronological age, menarche age and personal history of breast cancer were the only significant determinants of mammography history. The likelihood of previous mammography screening increased by a factor of 1.07 for every year older chronologically $(\mathrm{OR}=1.07$, 95\% CI: 1.00-1.14) and decreased by a factor of 1.12 for every year older at menarche $(\mathrm{OR}=0.89,95 \% \mathrm{CI}$ : $0.80-0.99)$. Respondents who had previously been diagnosed with breast cancer were over six times more likely to have undergone mammography screening.

\section{Mediator effect}

Figure 1 illustrates the association between menarche age and mammography history in women who are currently eligible to screen (i.e. aged over 40 , or aged 25 to 39 with a family history). The figure shows that women with a history of mammography screening were more likely to have had menarche at a younger age in their youth, notably at $<11$ years $(11.5 \%$ vs. $7.9 \%)$ and at 12 years $(25 \%$ vs. $17 \%)$. We decided to exclude menopausal age from bootstrapping assessing mediator effects because of a large proportion of missing data ( $>53$ percentage of participants did not indicate their age at menopause). Bootstrapping using menarche age revealed a significant mediator effect, whereby age at first menstruation partly 'explained' the association between chronological age and mammography history $(a b=-0.01$, BCa CI: $-0.01,-0.00) .{ }^{28}$ This mediator effect was significant based on the conservative 'normal' theory (i.e. Sobel) test $(z=-2.04, p=0.042) .^{30}$ This mediator effect is illustrated in Figure 2. The figure shows that older women in general were more likely to have had a previous mammogram. However, this association was complicated by menarche age, in the sense that those older women who in their youth experienced menarche at an older age were less likely to have a prior history of mammography. Older age at menarche is associated with a lower risk of breast cancer, which might make mammography screening seem unnecessary to some chronologically older women who are eligible for mammography screening.

\section{Discussion}

The data show that certain age-related risk factors are implicated in previous mammography uptake in Nigerian women. It suggests health education initiatives to promote breast cancer awareness and the need for early detection may be having some success in encouraging mammograms for breast screening in asymptomatic women who have age-related risk factors for breast cancer. The data are

TABLE 2: Results of hierarchical logistic regression predicting mammography history from age-related risk factors and family history.

\begin{tabular}{|c|c|c|c|c|}
\hline \multirow[t]{3}{*}{ Variables } & \multicolumn{4}{|c|}{ Mammography history (yes/no) } \\
\hline & Step 1 & Step 2 & Step 3 & Step 4 \\
\hline & OR $(95 \% \mathrm{Cl})$ & OR $(95 \% \mathrm{Cl})$ & OR $(95 \% \mathrm{Cl})$ & OR $(95 \% \mathrm{Cl})$ \\
\hline \multicolumn{5}{|l|}{ Age-related risk factors } \\
\hline Age (chronological) & $1.05(0.99-1.12)$ & $1.07(1.00-1.14)^{*}$ & $1.07(1.00-1.14)^{*}$ & $1.07(1.00-1.14)^{*}$ \\
\hline Age (at first confinement) & $1.00(0.95-1.05)$ & $1.00(0.95-1.04)$ & $1.00(0.95-1.04)$ & $1.00(0.95-1.04)$ \\
\hline Age (at menarche) & $0.91(0.83-1.01)$ & $0.89(0.80-0.99)^{*}$ & $0.89(0.80-0.99)^{*}$ & $0.89(0.80-0.99)^{*}$ \\
\hline Age (at menopause) & $1.04(0.94-1.14)$ & $1.01(0.92-1.11)$ & $1.01(0.92-1.11)$ & $1.01(0.91-1.11)$ \\
\hline \multicolumn{5}{|l|}{ History of breast cancer } \\
\hline Personal history of breast cancer & - & $6.12(2.50-14.99)^{* * *}$ & $6.11(2.49-14.97)^{* * *}$ & $6.10(2.49-14.96)^{* * *}$ \\
\hline Family history of breast cancer (general) & - & - & $1.32(0.33-5.20)$ & $1.13(0.12-10.31)$ \\
\hline Family history of breast cancer (first-degree relative with breast cancer) & - & - & - & $1.29(0.08-19.95)$ \\
\hline \multicolumn{5}{|l|}{ Model statistics } \\
\hline$\chi^{2}$ Step & 8.05 & $14.70^{* * *}$ & 0.15 & 0.03 \\
\hline$\chi^{2}$ Block & 8.05 & $14.70^{* * *}$ & 0.15 & 0.03 \\
\hline Nagelkerke $R^{2}$ & 0.05 & 0.16 & 0.16 & 0.16 \\
\hline Hosmer \& Lemeshow & 11.46 & $18.14^{*}$ & 14.97 & 13.85 \\
\hline
\end{tabular}

Note: The 'Steps' mentioned here refer to the different stages of the hierarchical regression analysis.

$\mathrm{OR}$, odds ratio; $\mathrm{Cl}$, confidence interval.

$*, p<0.05 ; * *, p<0.01 ; * * *, p<0.001$. 


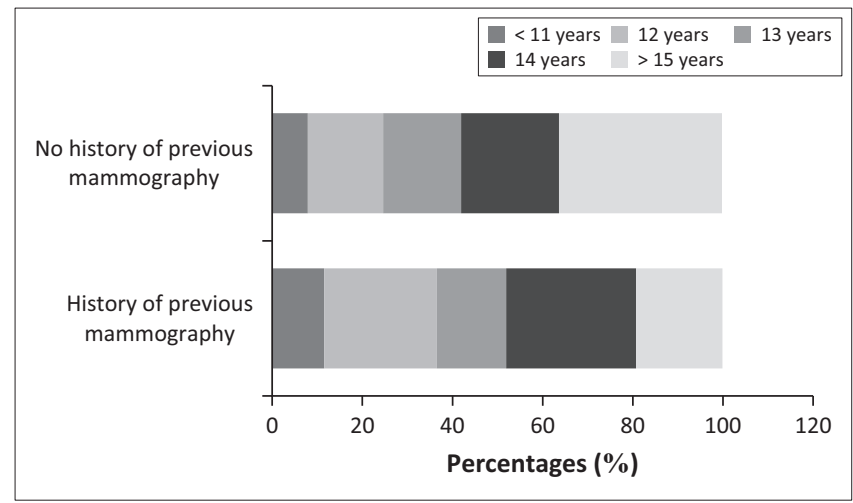

FIGURE 1: The association between menarche age in one's youth and mammography history.

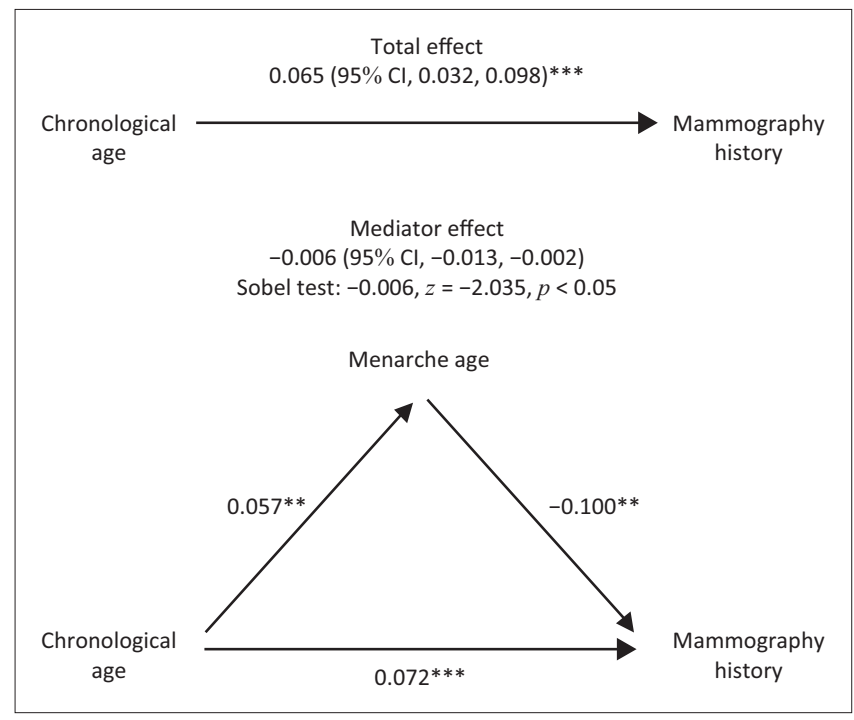

$*, p<0.05 ; * *, p<0.01 ; * * *, p<0.001$.

FIGURE 2: The relationships between chronological age, menarche age and mammography history.

consistent with health workers encouraging mammography screening via public awareness jingles. Women with adverse age-related risk factors may be motivated to have a mammogram, in response to the health promotion campaign. However, it is noteworthy that age at menopause was not associated with mammography history, perhaps highlighting the need for health education jingles specifically addressing menopausal risk. ${ }^{24}$

\section{Educational implications for chronological age}

Chronologically older women were more likely to undergo mammograms. This is consistent with evidence from Western populations. ${ }^{23}$ Nevertheless, it is important for health education programmes to emphasise that breast cancer tends to be diagnosed at a young age amongst Nigerian women (aged below 50 years), ${ }^{12}$ albeit the efficacy of mammography screening in younger women is questionable (because of greater breast density). Although knowledge of breast cancer risk factors in Nigerian women is low, and this has been implicated in low levels of mammography uptake, ${ }^{15}$ the positive relationship between chronological age and mammography history suggests older women were motivated to seek mammograms as a result of awareness of age-related risk factors. ${ }^{19}$ The public awareness jingles used by health workers seemed particularly helpful in this context. Even women younger than 50 years should be specifically targeted by such health promotion campaigns, given the lower age of breast cancer onset in Nigerian women. ${ }^{12}$ Lower uptake of mammography amongst younger women may contribute to the high proportion of advanced (stage III or IV) breast cancer cases reported in Nigeria (the highest in Africa), ${ }^{10}$ because breast pathology may remain undetected for years.

\section{Educational implications for age at menarche}

Previous studies suggest younger age of menarche is associated with elevated breast cancer risk in Nigerian women. ${ }^{13}$ The present findings indicate menarche age also relates to mammography history, with previous mammograms more likely in women of a younger menarche age. Again, this arguably depicts efforts by health providers to increase breast cancer awareness or deliberate efforts by the women themselves to seek mammography (given their elevated risk) in response to the health promotion jingles. Previous studies show low or modest knowledge of risk factors for breast cancer in Nigerian women, ${ }^{15,19,20}$ which in turn is blamed for low levels of mammography uptake..$^{15}$ Although the present findings suggest women of younger menarche age were motivated to request mammograms, presumably in response to the public awareness jingles, it is still necessary for health campaigns to address the patriarchal aspects of Nigerian society, where women are less able to take the initiative for their own health care..$^{22}$ The mediating effect of menarche age reinforces the need to educate older women who are eligible for screening about the importance of obtaining a mammogram even if they feel their risk of breast cancer is lower because of being older at menarche in their youth. ${ }^{31}$

\section{Educational implications for menopausal age}

The lack of association between menopausal age and mammography history is worrying ${ }^{9}$ and may highlight a knowledge deficit about breast cancer risk in Nigerian women. ${ }^{20}$ It perhaps indicates the need for public awareness jingles that explicitly emphasise the importance of menopausal age in breast cancer risk. ${ }^{24}$ Evidence suggests women who seek mammograms tend to be individuals with a family history of breast cancer, women with a history of breast pathologies or those who had already experienced clinical breast examination. ${ }^{15}$ Thus, educational initiatives should encourage women to seek mammography based on older menopausal age. This is particularly critical given that use of medical services for menopause-related problems is low amongst Nigerian women. ${ }^{24}$ Hence, awareness of a link between older menopausal age and breast cancer seems unlikely to motivate women to visit a hospital for mammography, unless more educational resources are committed to bridge the gap between knowledge and behaviour. ${ }^{15}$ Factors such as poverty, limited access to health services and reliance on traditional healers may present further challenges, diminishing likelihood of mammography. ${ }^{22}$ 


\section{Limitations}

The cross-sectional design negates conclusive inferences about possible directions of causality. The sample is also biased. Much of the Shell-Iyienu Mission breast cancerscreening programme is subsidised, making it affordable to many women within the catchment area. However, some women in the locality are unable to afford fees to participate in the programme, thus limiting the sample size. The study population would have been much larger had the programme been cost free. The sample comprised women within southeastern Nigeria, and hence may not necessarily reflect the country as a whole.

\section{Conclusions}

In summary, the present study associates certain age-related risk factors (age at menarche and chronological age) for breast cancer with a history of mammography uptake in Nigerian women. This link may partly denote the effect of a public awareness jingle to improve knowledge of breast cancer in Nigerian women. Women may have been motivated to request mammograms because of age-related concerns, notwithstanding previous research suggesting knowledge of risk factors for breast cancer is low amongst Nigerian women. The lack of an association between menopausal age and mammography history is a concern and may partly reflect cultural taboos and sensitivities. Research shows that Nigerian women are disinclined to use medical services for health problems related to menopause. Thus, it is essential for health education programmes in Nigeria to increase awareness of age-related risk factors for breast cancer, notably older age at menopause, and commit more resources to ensure this knowledge translates into higher mammography uptake.

\section{Acknowledgements}

We would like to thank the Radiology Department of Nnamdi Azikiwe University, Nigeria, for providing the data sets.

\section{Competing interests}

All the authors would like to issue a joint declaration that they do not have any conflict of interest with regard to the writing of this article.

\section{Authors' contributions}

E.O.U. was the project leader, while U.R.E., C.F.E. and C.N.A. assisted with recruitment and data collection. K.F.U. performed all of the statistical analysis on data sets provided by E.O.U. and made conceptual contributions to the article.

\section{References}

1. Ferlay J, Shin HR, Bray F, Forman D, Mathers C, Parkin DM. Estimates of worldwide burden of cancer in 2008: GLOBOCAN 2008. Int J Cancer. 2010;127(12):2893-2917. https://doi.org/10.1002/ijc.25516

2. GLOBOCAN 2012: Estimated cancer incidence, mortality and prevalence worldwide in 2012 [Internet]. IARC. 2016 [cited 2016 Nov 16]. Available from: http://globocan.iarc.fr/Pages/fact_sheets_cancer.aspx
3. Autier P, Boniol M. Mammography screening: A major issue in medicine. Eur J Cancer. 2018;90:34-62. https://doi.org/10.1016/j.ejca.2017.11.002

4. Lawal O, Murphy FJ, Hogg P, Irurhe N, Nightingale J. Mammography screening in Nigeria - A critical comparison to other countries. Radiography. 2015;21(4):348-351. https://doi.org/10.1016/j.radi.2015.03.015

5. Akhigbe AO, Akinola RA, Ighodaro EO. Screening mammography findings among some Nigerian women. J Adv Med Med Res. 2017;24(6):1-7. https://doi.org/ 10.9734/JAMMR/2017/37132

6. Checka CM, Chun JE, Schnabel FR, Lee J, Toth $\mathrm{H}$. The relationship of mammographic density and age: Implications for breast cancer screening. Am J Roentgenol. 2012;198(3):W292-W295. https://doi.org/10.2214/AJR.10.6049

7. Onitilo AA, Engel JM, Liang $\mathrm{H}$, et al. Mammography utilization: Patien characteristics and breast cancer stage at diagnosis. Am J Roentgenol. 2013;201(5):1057-1063. https://doi.org/10.2214/AJR.13.10733

8. Okobia MN, Bunker $\mathrm{CH}$. Epidemiological risk factors for breast cancer - A review. Niger J Clin Pract. 2005;8(1):35-42.

9. Britt K. Menarche, menopause, and breast cancer risk. Lancet Oncol. 2012;13(11):1071-1072. https://doi.org/10.1016/S1470-2045(12)70456-4

10. Jedy-Agba E, McCormack V, Adebamowo CA, Dos-Santos-Silva I. Stage at diagnosis of breast cancer in sub-Saharan Africa: A systematic review and meta-analysis. Lancet Glob Health. 2016;4:e923-e935. https://doi.org/10.1016/S2214-109X(16) 30259-5

11. Zagouri F, Sergentanis TN, Tsigginou A, et al. Female breast cancer in Europe: Statistics, diagnosis and treatment modalities. J Thorac Dis. 2014;6(6):589-590.

12. Sighoko D, Kamate B, Traore C, et al. Breast cancer in pre-menopausal women in West Africa: Analysis of temporal trends and evaluation of risk factors associated with reproductive life. Breast. 2013;22(5):828-835. https://doi.org/10.1016/j. with reproductive
breast.2013.02.011

13. Huo D, Adebamowo CA, Ogundiran TO, et al. Parity and breastfeeding are protective against breast cancer in Nigerian women. Br J Cancer. 2008:98(5):992-996. https:// doi.org/10.1038/sj.bjc.6604275

14. Beral V, Bull D, Pirie K, et al. Menarche, menopause, and breast cancer risk: Individual participant meta-analysis, including 118964 women with breast cance from 117 epidemiological studies. Lancet Oncol. 2012;13(11):1141-1151. https:// doi.org/10.1016/S1470-2045(12)70425-4

15. Olayide AS, Halimat AJ, Samuel OA, Ganiyu RA, Soliu OA. Level of awareness and knowledge of breast cancer in Nigeria. A systematic review. Ethiop J Health Sci. 2017;27(2):163-174. https://doi.org/10.4314/ejhs.v27i2.9

16. Akhigbe $\mathrm{AO}$, Omuemu VO. Knowledge, attitudes and practice of breast cancer screening among female health workers in a Nigerian urban city. BMC Cancer. 2009;9:203. https://doi.org/10.1186/1471-2407-9-203

17. Oluwole OC. Awareness, knowledge, and practice of breast-self-examination amongst female health workers in a Nigerian community. Sudan JMS. 2008;3(2): 99-103.

18. Gabriel OE, Ajetunmobi OA, Shabi OM, et al. Awareness and practice of self breast examination among female nurses at the Federal Teaching Hospital Ido-Ekiti, Nigeria. J Public Health Afr. 2016;7(1):11-14. https://doi.org/10.4081/jphia. 2016.528

19. Ibrahim NA, Oludara MA. Socio-demographic factors and reasons associated with delay in breast cancer presentation: A study in Nigerian women. Breast. 2012;21(3):416-418. https://doi.org/10.1016/j.breast.2012.02.006

20. Okobia MN, Bunker $\mathrm{CH}$, Okonofua FE, Osime U. Knowledge, attitude and practice of Nigerian women towards breast cancer: A cross-sectional study. World J Surg Oncol. 2006;4:11. https://doi.org/10.1186/1477-7819-4-11

21. Wernher I, Lipsky MS. Psychological theories of aging. Dis Mon. 2015;61(11):480488. https://doi.org/10.1016/j.disamonth.2015.09.004

22. Brinton LA, Figueroa JD, Awuah B, et al. Breast cancer in sub-Saharan Africa: Opportunities for prevention. Breast Cancer Res Tr. 2014;144(3):467-478. https:// doi.org/10.1007/s10549-014-2868-z

23. Missinne S, Bracke P. Age differences in mammography screening reconsidered: Life course trajectories in 13 European countries. Eur J Public Health. 2015;25(2):314-320. https://doi.org/10.1093/eurpub/cku077

24. Ozumba BC, Obi SN, Obikili E, Waboso P. Age, symptoms, and perception of menopause among Nigerian women. J Obstet Gynecol India. 2004;54(6):575-578.

25. Forman MR, Mangini LD, Thelus-Jean R, Hayward MD. Life-course origins of the ages at menarche and menopause. Adolesc Health Med Ther. 2013;4:1-21. https://doi.org/10.2147/AHMT.S15946

26. Skinner MK. Regulation of primordial follicle assembly and development. Hum Reprod Update. 2005;11(5):461-471. https://doi.org/10.1093/humupd/dmi020

27. Hayes AF. Beyond Baron and Kenny: Statistical mediation analysis in the new millennium. Commun Monogr. 2009;76:408-420. https://doi.org/10.1080/03637 750903310360

28. Hayes AF. Introduction to mediation, moderation, and conditional process analysis: A regression-based approach. New York: The Guilford Press; 2013.

29. Mackinnon DP, Warsi G, Dwyer JH. A simulation study of mediated effect measures. Multivar Behav Res. 1995;30(1):41-62. https://doi.org/10.1207/ s15327906mbr3001_3

30. MacKinnon DP, Lockwood CM, Hoffman JM, West SG, Sheets V. A comparison of methods to test mediation and other intervening variable effects. Psycho Methods. 2002;7(1):83-104. https://doi.org/10.1037/1082-989X.7.1.83

31. Alexeeff SE, Odo NU, Lipson JA, et al. Age at menarche and late adolescent adiposity associated with mammographic density on processed digital mammograms in 24,840 women. Cancer Epidemiol Biomarkers Prev. 2017;26(9): 1450-1458. https://doi.org/10.1158/1055-9965.EPI-17-0264 